\title{
ANÁLISE DO DESGASTE NA INTERFACE DE PARES TRIBOLÓGICOS FORMADOS PELO AÇO FERRAMENTA AISI M2 NITRETADO A PLASMA E AÇO INOXIDÁVEL AISI 316*
}

\section{Resumo}

Lucas Travi ${ }^{1}$

Vanessa Moura de Souza²

Leandro Brunholi ${ }^{3}$

Alexandre da Silva Rocha ${ }^{4}$ Célia de Fraga Malfatti ${ }^{5}$

Os problemas gerados no processamento do aço inoxidável AISI 316 são um grande problema do setor metal mecânico, por exemplo, no processo de usinagem, onde o material sofre altas taxas de deformação plástica e elevadas temperaturas na região de contato ferramenta-peça. Além disso, a adesão de aço inoxidável em materiais de maior dureza, no caso a ferramenta, também são problemas enfrentados. Neste trabalho foi feito um estudo qualitativo em escala laboratorial do contato entre um material de maior dureza (aço AISI M2 nitretado a plasma) e o aço AISI 316. Foram realizados ensaios de microdureza Vickers e rugosidade afim de caracterizar as amostras de aço AISI M2. Ensaios tribológicos do tipo Ball-on-Plate foram realizados com a finalidade de determinar o coeficiente de atrito ao longo do tempo para os pares tribológicos formados. Análises feitas via MEV/EDS foram feitas tanto nas trilhas geradas nas superfícies das amostras quanto nas esferas, para detectar pontos de adesão, deformação plástica e transferência de material entre as duas superfícies. Ficou comprovado que a nitretação a plasma com gaiola catódica proporcionou um menor coeficiente de atrito ao longo do tempo quando posta em contato com a esfera de aço inoxidável, bem como foi possível observar a formação de uma menor quantidade de pontos de adesão de aço inoxidável para esta superfície.

Palavras-chave: Tribologia; Nitretação a plasma; Usinagem; Coeficiente de atrito.

\section{ANALYSIS OF WEAR IN THE TRIBOLOGICAL PAIRS INTERFACE FORMED BY PLASMA NITRIDED AISI M2 STEEL AND AISI 316 STAINLESS STEEL}

\section{Abstract}

Problems generated in stainless steel AISI 316 processing are a serious issue of the metalmechanical industry sector, for example, at the machining process, in which the material undergoes high strain rates and high temperatures on the tool-piece interface. Furthermore, the stainless steel adhesion in the harder material (the tool) are also an encountered problem. This work was done a qualitative study in laboratory scale of the contact between a higher hardness material (plasma nitrided AISI M2) and the stainless steel AISI 316. In order to characterize the AISI M2 samples, measurements of Vickers and surface roughness were done for every sort of nitrided surface. Ball-on-Plate tribological tests were carried out to determine the friction coefficient over the time for the tribological pairs. The generated trails and the worn spheres were characterized by SEM and energy dispersive $\mathrm{x}$-Ray analysis to detect points of adhesion, plastic deformation and material transfer between the surfaces. It was proven that the cathodic cage plasma nitriding resulted in a lower friction coefficient when in contact with the stainless steel sphere, moreover it was possible to observe the formation of fewer bonding points of stainless steel at this kind of surface.

Keywords: Tribology; Plasma nitriding; Machining; Friction.

1 Engenheiro Metalúrgico, Mestre em engenharia, Universidade Federal do Rio Grande do Sul (UFRGS), Porto Alegre, Rio Grande do Sul, Brasil.

Engenheira Mecânica, Mestranda, Processos de Fabricação, UFRGS, Porto Alegre, RS, Brasil.

Eng. Metalúrgico, Mestrando, Universidade Federal do Rio Grande do Sul, Porto Alegre, RS, Brasil.

Engenheiro Mecânico, Doutor, Professor, Processos de Fabricação, UFRGS, Porto Alegre, RS, Brasil.

Eng. Metalúrgica, Doutora, Professora, UFRGS, Porto Alegre, RS, Brasil. 


\section{INTRODUÇÃO}

A elevada resistência à corrosão dos aços inoxidáveis austeníticos tipo AISI 316 permite uma uma vasta aplicação em diversos componentes nas indústrias químicas, petrolíferas, biomédicas e automobilísticas. A microestrutura austenítica monofásica livre de carbonetos, associada à presença de alto teor do elemento níquel em sua composição química (responsável pela estabilização da fase austenítica) proporcionam melhores propriedades frente à corrosão que aços ao carbono ou ainda outros aços inoxidáveis, como os ferríticos e os martensíicos. Todavia, a operação e o processamento dessa liga em certas faixas de temperatura $\left(490^{\circ} \mathrm{C}\right.$ a $900^{\circ} \mathrm{C}$ por um certo tempo) [1] é um problema, já que ocorre a formação de carbonetos do tipo M23C6 no contornos de grãos, podendo haver a formação de carbonetos de cromo (Cr23C6) e, consequentemente, empobrecendo de cromo a região ao redor ,deixando os contornos de grão susceptíveis a corrosão, ocorrendo a chamada corrosão intergranular. $\mathrm{O}$ controle da temperatura no processamento deste material, portanto, é de grande importância para manter as suas propriedades originais da liga referente à corrosão [2,3]. Além disso, a liga de aço inoxidável AISI 316 pode apresentar problemas de desgaste adesivo e deformação plástica severa quando posta em contato com materiais de durezas mais elevadas. [4]

A usinagem é um processo de fabricação que pode gerar elevadas temperaturas e deformações ao componente que está sendo produzido devido ao fato de dois corpos (peça e ferramenta) estarem em contato e em movimento relativo de alta velocidade de rotação. Sendo assim, quanto menor a friç̧ão entre os dois corpos ao longo do processo, menor será a probabilidade de formar fases que irão prejudicar a resistência à corrosão do aço inoxidável AISI 316.[5] Uma boa forma de reduzir a fricção entre dois corpos, é diminuir a adesão entre as superfícies dos mesmos, por isso, a usinagem dessas ligas ferrosas com ferramentas de aços rápidos requer grandes cuidados. Tratamentos superficiais como a nitretação a plasma da ferramenta tem como um dos objetivos reduzir o contato metal-metal na interface ferramenta-peça são comumente utilizados para aplicações industriais. A camada nitretada formada irá diminuir o contato metal-metal, além de aumentar a dureza superficial da ferramenta, logo suas asperezas cisalham mais facilmente nas asperezas da peça de aço inoxidável, melhorando o acabamento superficial da peça usinada e aumentando a vida em desgaste da ferramenta de corte. [6-11]. Contudo, o incremento na dureza propiciado pela nitretação a plasma vem acompanhado de um aumento na rugosidade superficial da ferramenta devido ao bombardeamento iônico que a sua superfície irá sofrer. [12-15] Esta maior rugosidade superficial, após o tratamento, poderá acabar aumentando a fricção devido ao maior contato entre as asperezas de ambas as superfícies, e com isso, aumentando a adesão entre as superfícies e a temperatura gerada na interface ferramenta-peça. $[12,16]$

Com objetivo de proporcionar um incremento na dureza superficial e manter uma baixa rugosidade superficial, foi desenvolvida a nitretação a plasma com gaiola catódica. Neste método de nitretação a plasma as amostras estão isoladas e envoltas por uma gaiola metálica cheia de furos, nos quais irão se formar os nitretos que serão depositados na superfície da ferramenta. O aquecimento homogêneo ao longo da ferramenta também irá proporcionar a formação de uma camada nitretada homogênea. O conceito da nitretação a plasma com gaiola catódica é baseado em utilizar as boas propriedades mecânicas da nitretação a plasma convencional aliadas a uma melhoria no aspecto tribológico das superfícies associado a uma menor rugosidade superficial após o tratamento. [17-21] 
Este trabalho irá analisar qualitativamente, em escala laboratorial, a importância no incremento da dureza superficial de uma amostra de aço rápido AISI M2 aliado com a sua rugosidade superficial após o tratamento de nitretação a plasma com e sem gaiola catódica. A análise feita neste estudo irá se preocupar com fenômenos como fricção, transferências de material e cisalhamento, que ocorrem na interface ferramenta-peça.

\section{MATERIAIS E MÉTODOS}

As amostras de aço ferramenta AISI M2 contendo $31,5 \mathrm{~mm}$ de diâmetro e $5 \mathrm{~mm}$ de altura tiveram sua superfície preparada através de lixamento (lixas de MESH 80 a $1200)$ e posterior polimento com pasta diamantada $(1 \mu \mathrm{m})$ até obterem o acabamento desejado. A composição das amostras utilizadas foi obtida através de espectroscopia de emissão óptica. As esferas empregadas neste estudo possuem 4,73 $\mathrm{mm}$ de diâmetro e acabamento superficial polido, a composição química das mesmas foi informada pelo fabricante. A Tabela 1 possui a composição dos materiais utilizados neste estudo.

Tabela 1. Composição do aço AISI M2 medida via espectroscopia de emissão óptica

\begin{tabular}{|c|c|c|c|c|c|}
\hline AISI M2 & Elemento & $\mathbf{\%}$ & AISI 316 & Elemento & \% \\
\hline & $\mathbf{C}$ & 1,00 & & $\mathbf{C}$ & 0,08 \\
\hline & $\mathbf{S i}$ & 0,33 & & $\mathbf{S i}$ & 1,00 \\
\hline & $\mathbf{M n}$ & 0,24 & & $\mathbf{M n}$ & 2,00 \\
\hline & $\mathbf{P}$ & 0,02 & & $\mathbf{P}$ & $\operatorname{max~0,04}$ \\
\hline & $\mathbf{S}$ & 0,01 & & $\mathbf{S}$ & $\operatorname{max~0,03}$ \\
\hline & $\mathbf{C r}$ & 3,17 & & $\mathbf{N i}$ & 10 a 14 \\
\hline & $\mathbf{M o}$ & 4,66 & & $\mathbf{C r}$ & 16 a 18 \\
\hline & $\mathbf{V}$ & 1,5 & & $\mathbf{M o}$ & 2 a 3 \\
\hline & $\mathbf{W}$ & 6,44 & & $\mathbf{F e}$ & Restante \\
\hline & $\mathbf{S n}$ & 0,01 & & - & - \\
\hline & $\mathbf{F e}$ & 82,63 & & - & - \\
\hline
\end{tabular}

A Tabela 2 apresenta um resumo da nomenclatura empregada neste trabalho, relacionando cada tipo de superfície com seu respectivo tratamento superficial. A nitretação a plasma das amostras foi realizada através de dois métodos diferentes (convencional e gaiola catódica), com mistura gasosa de $76 \% \mathrm{~N} 2-24 \% \mathrm{H} 2$, temperatura de $420^{\circ} \mathrm{C}$ e 30 minutos de nitretação. Demais parâmetros utilizados podem ser vistos nas Tabela 3 e 4.

Tabela 2. Nomenclaturas empregadas para cada tipo de superfície tratada

\begin{tabular}{|c|c|}
\hline Nome & Tratamento Superficial \\
\hline POLIDA & - \\
\hline $75 \mathrm{C}$ & $76 \% \mathrm{~N}_{2}-24 \% \mathrm{H}_{2}-$ Convencional \\
\hline $75 \mathrm{G}$ & $76 \% \mathrm{~N}_{2}-24 \% \mathrm{H}_{2}-$ Com Gaiola Catódica $^{2}$ \\
\hline
\end{tabular}


Tabela 3. Parâmetros utilizados na nitretação a plasma convencional.

\begin{tabular}{|c|c|c|c|}
\hline $\mathbf{7 6} \% \mathbf{~ N}_{\mathbf{2}} \mathbf{- 2 4} \% \mathbf{H}_{\mathbf{2}}$ & $\begin{array}{c}\text { Pressão } \\
{[\mathrm{mbar}]}\end{array}$ & $\begin{array}{c}\text { Tensão } \\
\text { [V] }\end{array}$ & $\begin{array}{c}\text { Tempo } \\
\text { [min] }\end{array}$ \\
\hline Nitretação & 3,5 & $\sim 350$ & 30 \\
\hline Aquecimento & 3 & $\sim 300$ & \\
\hline Sputtering & 0,5 & $\sim 550$ & 30 \\
\hline
\end{tabular}

Tabela 4. Parâmetros utilizados na nitretação a plasma com gaiola catódica

\begin{tabular}{|c|c|c|c|}
\hline $\mathbf{7 6 \%} \mathbf{N}_{\mathbf{2}} \mathbf{- 2 4 \%} \mathrm{H}_{\mathbf{2}}$ & $\begin{array}{c}\text { Pressão } \\
\text { [mbar] }\end{array}$ & $\begin{array}{c}\text { Tensão } \\
{[\mathbf{V}]}\end{array}$ & $\begin{array}{c}\text { Tempo } \\
\text { [min] }\end{array}$ \\
\hline Nitretação & 3,5 & $\sim 350$ & 30 \\
\hline Aquecimento & 3 & $\sim 350$ & \\
\hline Sputtering & 0,5 & $\sim 550$ & 30 \\
\hline
\end{tabular}

A dureza superficial das amostras foi feita por meio de microindentações Vickers com variação de carga $(25,50,100,200$ e 300 gf). Foi utilizado um microdurometro ISHTVD1000. A rugosidade superficial média $(\mathrm{Ra})$ foi medida com um rugosímetro Mitutoyo Surftest-401, a Ra para cada tipo de superfície foi determinada a partir de 10 medições em cada tipo de superfície (como polida, 75C e 75G).

A medição do coeficiente de atrito será feita através do método Ball-on-Flat (Figura 1) em um tribômetro CETR-UMT. Este método consiste basicamente no contato entre uma esfera e uma amostra plana, com uma carga constante aplicada. Os dois corpos deslizam entre si formando uma trilha na amostra plana e desgastando a esfera. Quanto maior a carga aplicada, a tendência é que maior seja a área de contato entre os dois corpos, formando trilhas mais espessas e desgastando uma maior área da esfera. A velocidade é outro parâmetro variável neste procedimento, para o equipamento utilizado a velocidade é dada em forma de frequência e medida em $\mathrm{Hz}$. Foram aplicadas carga de $6 \mathrm{~N}$ e frequência de $4 \mathrm{~Hz}$, praticamente as máximas permitidas pelo equipamento, sendo realizadas triplicatas dos ensaios, buscando aumentar a confiabilidade dos resultados obtidos. Todos os ensaios tiveram 30 minutos de duração e foram realizados a seco, com temperatura de $20^{\circ} \mathrm{C}$ e umidade relativa do ar entre 60 e $70 \%$. Além disso, todas as amostras foram limpas com álcool isopropílico antes dos ensaios. As esferas passaram por um banho ultrassônico de álcool isopropílico por 10 minutos. Foi utilizada uma esfera para cada ensaio.

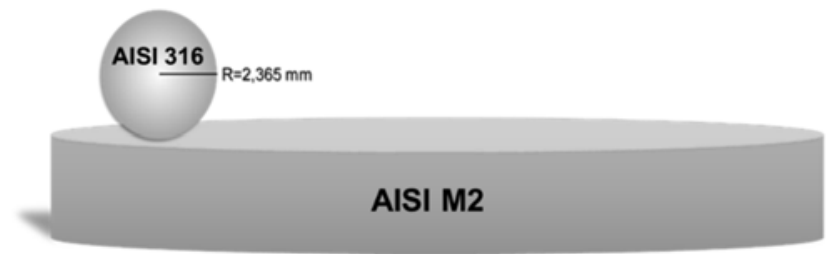

Figura 1. Esquema do sistema Ball-on-Flat

Um microscópio eletrônico de varredura (MEV) foi empregado para obter imagens das trilhas geradas nas amostras durante os ensaios tribológicos, as áreas desgastadas nas esferas também foram caracterizadas (Figura 2). Para analisar as esferas desgastadas foram utilizados elétrons secundários, um aumento maior foi dado na região que aparentasse ter pontos de maior deformação plástica ou adesão, e consequentemente, pior acabamento superficial. Nas amostras foram utilizados elétrons retroespalhados para que o contraste devido a composição química fosse gerado, possibilitando a análise de pontos de adesão dentro da trilha. O microscópio eletrônico de varredura utilizado foi um XL 30 da Philips com microssonda EDS para 
analise elementar acoplada. A espectrometria de raios $X$ por dispersão de energia (EDS) foi utilizado em conjunto com o MEV afim de qualificar a transferência de material entre as duas superfícies, foram feitas medições tanto nas trilhas das amostras quanto nas áreas desgastadas das esferas.
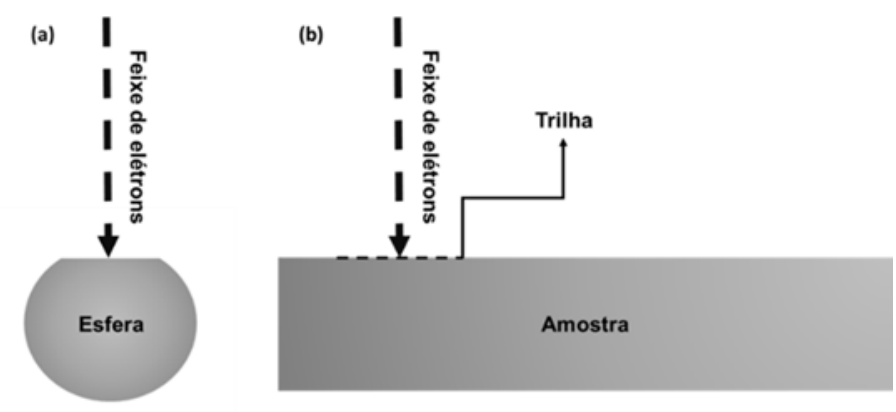

Figura 2. Vista esquemática do feixe de elétrons incidente sobre (a) esfera de AISI 316 e (b) trilhas formadas na superfície do aço AISI M2

\section{RESULTADOS E DISCUSSÃO}

Como pode-se ver na Figura 3, a nitretação provocou um incremento praticamente igual na dureza superficial das amostras de aço rápido nitretadas, além disso é possível notar que com o aumento da profundidade da indentação Vickers tem-se uma redução dos valores de dureza, até chegar ao valor do substrato do material. Devido aos baixos tempo e temperatura de tratamento as camadas formadas foram bastante finas, o que é aconselhável para a nitretação de aços ferramenta. [10]

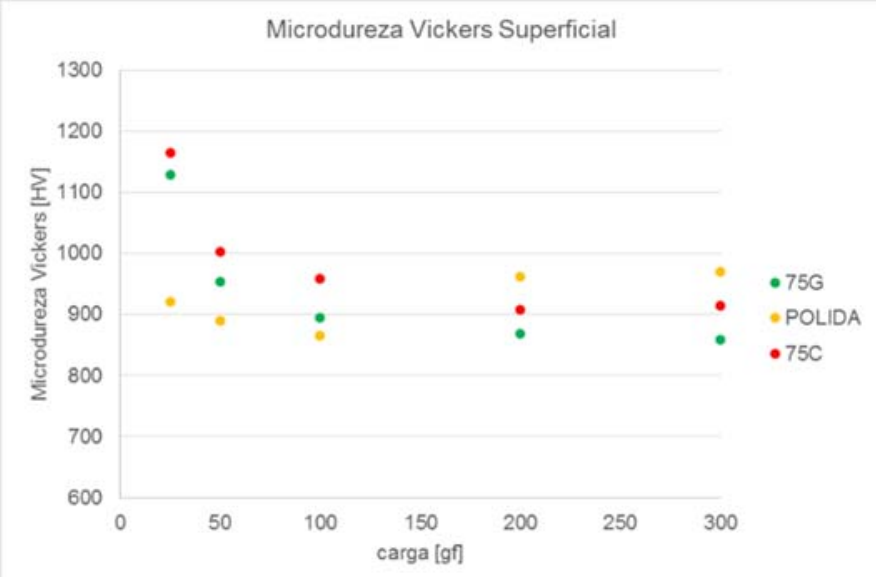

Figura 3. Valores de microdureza Vickers variando a carga

A partir dos resultados de rugosidade superficial média (Ra) (Figura 5) fica nítida a modificação superficial causada pelo bombardeamento iônico do plasma. Enquanto a amostra nitretada com o uso da gaiola catódica apresenta um aumento de aproximadamente $20 \%$ em sua rugosidade superficial, a amostra nitretada com processo convencional demonstrou um aumento de $107 \%$ na sua rugosidade superficial. A formação da camada nitretada através do processo convencional provocou grandes alterações na topografia da amostra, fazendo com que ela perdesse as boas propriedades tribológicas de uma superfície polida, enquanto isso, a expectativa é que essas boas propriedades tribológicas mantenham-se na amostra nitretada com gaiola catódica, associadas ainda a um aumento na dureza superficial. Souza et al [19] também demonstrou que a nitretação a plasma com gaiola catódica 
geraria uma superfície com rugosidade mais próxima da polida devido à menor modificação superficial proposta por este tratamento.

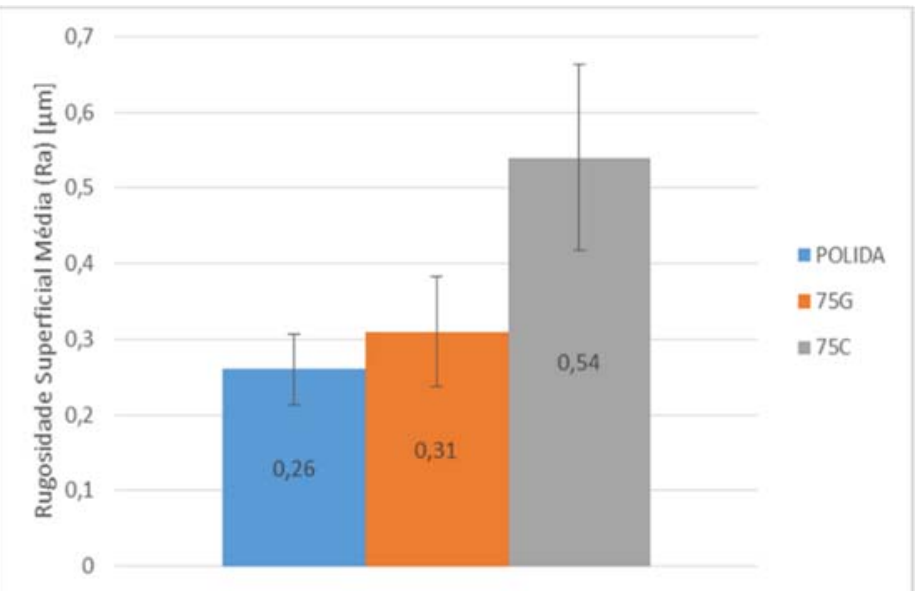

Figura 4. Valores de Ra obtidos para as superfícies

Na Figura 5 é possível constatar que os maiores valores de coeficiente de atrito pelo tempo foram obtidos para o par tribológico formado pela esfera de aço inoxidável e pela superfície de aço AISI M2 nitretada a plasma via processo convencional, demonstrando que o maior aumento na rugosidade superficial aumentou o contato entre as asperezas das duas superfícies, aumentando a força necessária para o sistema realizar o deslizamento. Também fica visível que a amostra nitretada com gaiola catódica apresentou os menores valores de coeficiente de atrito para praticamente todo o tempo de ensaio feito. Contudo, um maior coeficiente de atrito significa apenas que o sistema tribológico realizou uma força maior para realizar o deslizamento entre os dois corpos, por isso a análise posterior tanto de esfera quanto superfície da amostra deve ser feita. A importância de diminuir o coeficiente de atrito está diretamente ligada à redução da força que o sistema tribológico fará para realizar o deslizamento, o que é de grande importância para aplicações práticas tanto de usinagem quanto de conformação mecânica.

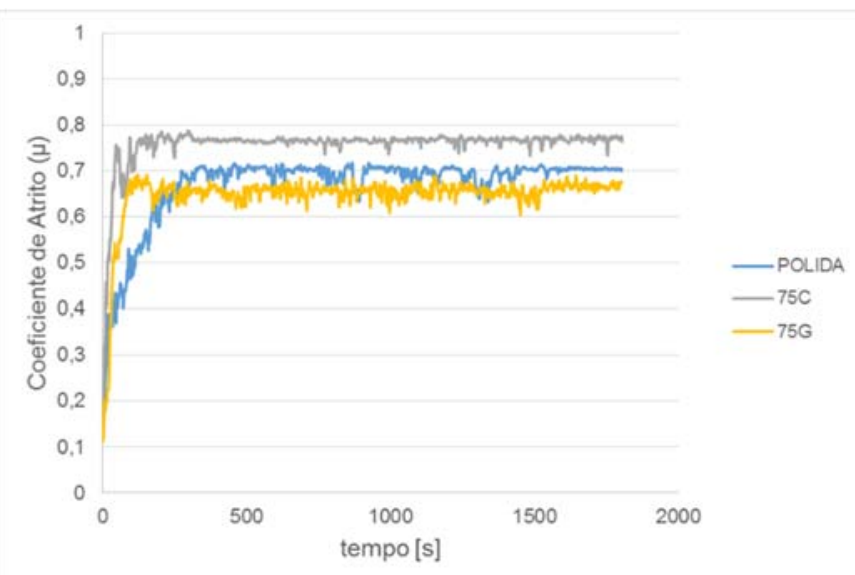

Figura 5. Gráfico de coeficiente de atrito obtido para os diferentes pares tribológicos

A análise feita no MEV foi de caráter conclusivo para averiguar o desgaste e a integridade superficial tanto na amostra de aço AISI M2 quanto na esfera de AISI 316. As imagens obtidas via MEV (Figura 6-8) na superfície das amostras demonstrou pontos de adesão de material da esfera de aço inoxidável para todas as amostras, 
porém com uma quantidade menor para a amostra nitretada via gaiola catódica, para a amostra polida foi possível ver uma área bem forte de adesão na região da ponta da trilha, enquanto a amostra nitretada com processo convencional demostra pontos de adesão em praticamente toda a trilha. Já para as imagens obtidas para as áreas desgastadas das esferas fica clara a importância da nitretação a plasma, enquanto a esfera colocada em contato com a superfície polida demonstrou uma região de fratura dúctil bem evidente, com microvacâncias e aspecto fibroso, as esferas postas em contato com as superfícies nitretadas apresentaram uma fratura por clivagem, demonstrando que a área foi cisalhada com maior eficácia.

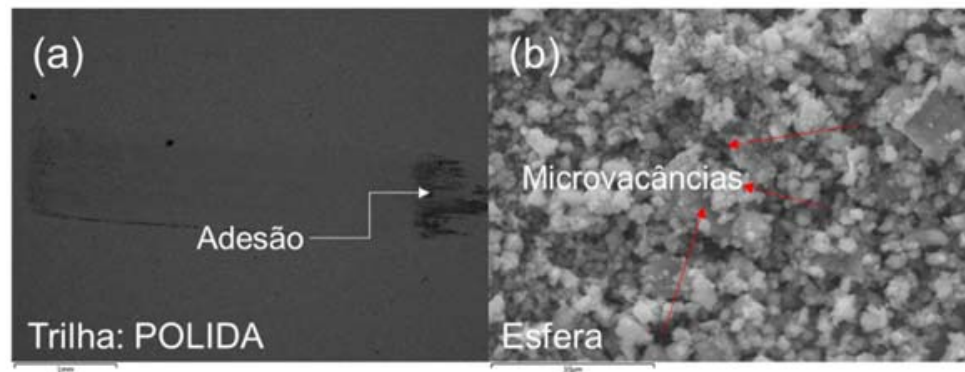

Figura 6. Imagem obtida via MEV da trilha de aço inoxidável na superfície do aço AISI M2 polida com aumento de 50x (a) e da área desgastada da esfera com aumento de $8000 x$ (b)

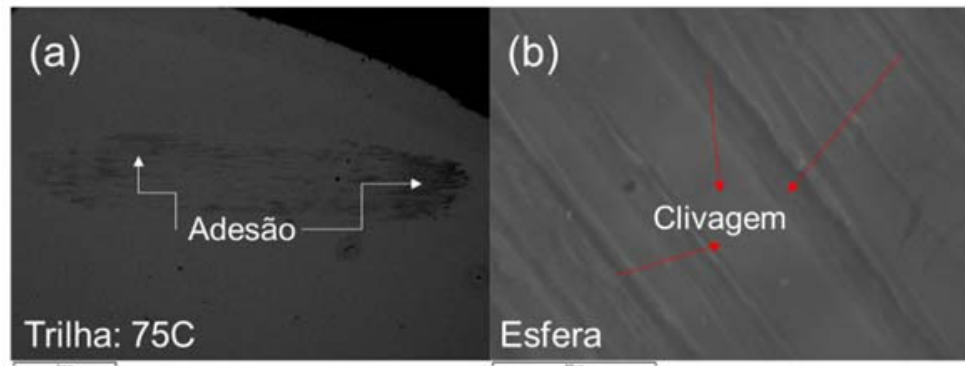

Figura 7. Imagem obtida via MEV da trilha de aço inoxidável na superfície do aço AISI M2 nitretada a plasma via processo convencional com aumento de 50x (a) e da área desgastada da esfera com aumento de $8000 x$ (b)

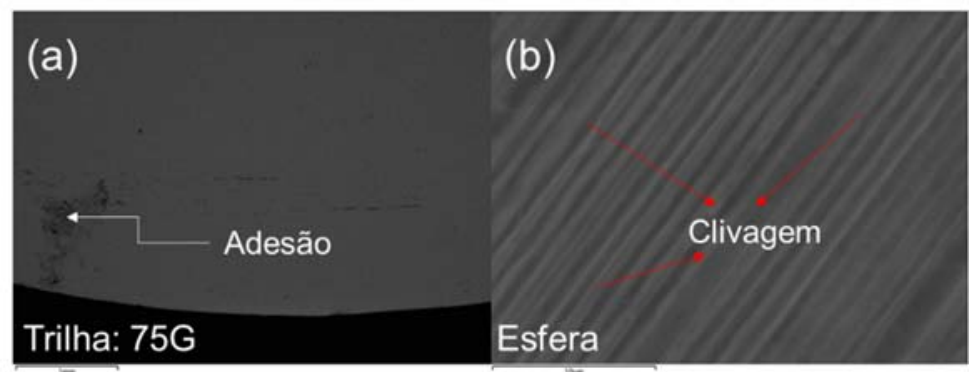

Figura 8. Imagem obtida via MEV da trilha de aço inoxidável na superfície do aço AISI M2 nitretada a plasma via processo convencional com aumento de 50x (a) e da área desgastada da esfera com aumento de $8000 x(b)$

As medições feitas via EDS feitas em imagens com maior magnitude na região das trilhas (Figura 9) comprovaram pontos de adesão de aço AISI 316, conforme é visto nos espectros. O aumento nos teores de cromo pode ser constatado através do aumento do pico deste elemento, a presença de níquel dentro da região mais escura também ajuda a comprovar a presença de aço inoxidável aderido nas superfícies das 
amostras de aço ferramenta AISI M2, tanto para as amostras nitretadas quanto para a polida.
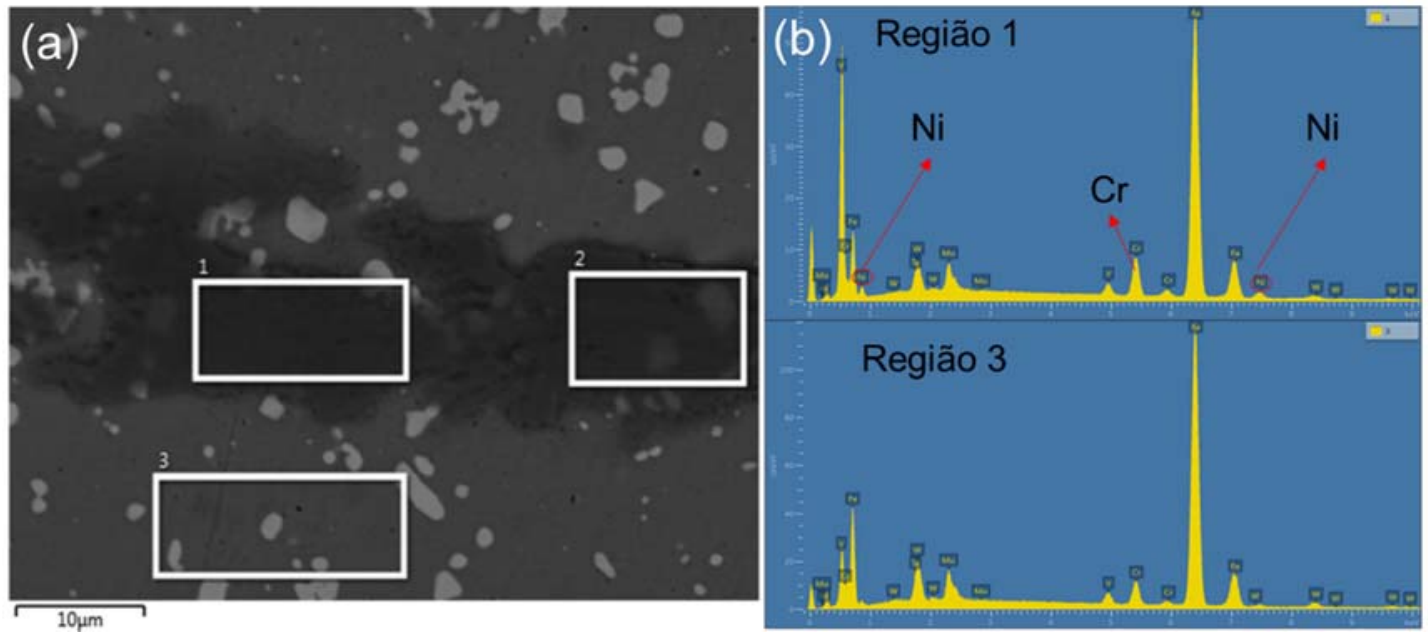

Figura 9. Imagem obtida via microscopia eletrônica de varredura da região da trilha com aumento de 4000x (a) e espectros obtidos via EDS (b)

Por outro lado, os espectros gerados para as medições feitas por EDS nas esferas não constataram elementos que pudessem sugerir a adesão de material das amostras de aço AISI M2, tanto para a polida quanto para as nitretadas. Comprovando que o aço AISI 316 pode apresentar problemas relacionados a desgaste adesivo em materiais de dureza mais elevada [4]. Experimentos similares feitos por Pujante et al [16].

\section{CONCLUSÃO}

- A nitretação a plasma gerou um incremento na dureza superficial das amostras de aço AISI M2, todavia o aumento excessivo na rugosidade superficial causado pelo bombardeamento iônico da nitretação a plasma convencional causou um aumento no valor de coeficiente de atrito ao longo do tempo;

- As esferas de aço inoxidável desgastadas pelas superfícies nitretadas apresentaram uma fratura frágil, enquanto na esfera desgastada pela superfície de aço AISI M2 polida foi possível observar pontos de fratura plástica;

- Os espectros gerados nas áreas desgastadas nas esferas não demonstraram nenhum pico característico de elementos que pudessem ser associados à adesão de AISI M2 nas esferas;

- Todas as superfícies de AISI M2 apresentaram pontos de adesão de aço inoxidável AISI 316, porém através de uma análise visual a superfície nitretada a plasma com gaiola catódica apresentou menos pontos de adesão. 


\section{Agradecimentos}

Os autores agradecem à CAPES e CNPQ pelas bolsas de pesquisa.

\section{REFERÊNCIAS}

1 Weiss B, Stickler R. Phase instabilities during high temperature exposure of 316 austenitic stainless steel. Metallurgical Transactions. 1972;3(4):851-866.

2 Matula M, Hyspecka K, Svobodab M, Vodareka V, Dagbertc C, Gallandc J, Stonawskaa Z, Tuma L. Intergranular corrosion of AISI $316 \mathrm{~L}$ steel. Materials Characterization. 2001;46(2-3):203-210.

3 Cramer SD, Covino BS. ASM Handbook Volume 13A: Corrosion: Fundamentals, Testing and Protection. Materials Park: ASM International; 2003.

4 Li CX, Bell T. Sliding wear properties of active screen plasma nitrided 316 austenitic stainless steel. Wear. 2004;256(11-12):1144-1152.

$5 \quad$ Davim JP. Surface Integrity in Machining. London: Springer-Verlag; 2010.

6 Davis JR. ASM Handbook Volume 16: Machining. Materials Park: ASM International; 1989.

7 Rocha AS. Influência do estado superficial prévio na nitretação a plasma do aço AISI M2. Porto Alegre: Doutorado UFRGS/PPGE3M; 2000.

8 Santos GR. Caracterização e avaliação do comportamento tribológico do aço ferramenta DIN X100CrMoV8-1-1 com tratamento dúplex. Porto Alegre: Doutorado UFRGS/PPGE3M; 2015.

9 Both GB. Caracterização e avaliação tribológica de superfícies resistentes ao desgaste para aplicação em ferramentas de conformação a frio. Porto Alegre: Mestrado UFRGS/PPGE3M; 2000.

10 Kwietniewski CE, Fontane W, Moraes C, Rocha AS, Hirsch T, Reguly A. Nitrided layer embrittlement due to the edge effect on duplex treated AISI M2 high-speed steel. Surface and Coatings Technology. 2004;179(1):27-32.

11 Jacobsen SD, Hinrichs R, Baumvol IJR, Castellano G, Vasconcellos, MAZ. Depth distribution of martensite in plasma nitrided AISI H13 steel and its correlation to hardness. Surface and Coatings Technology. 2015;270:266-271.

12 Menezes PL, Ingole SP, Nosonovski M, Kailas SV, Lovel MR. Tribology for scientists and engineers. New York: Springer-Verlag; 2013.

13 Davim JP. Tribology in manufacturing technology. Berlin: Springer-Verlag; 2013.

14 Astakhov PV. Tribology of metal cutting. Elsevier; 2006.

15 ASM. ASM Handbook Volume 4: Heat Treating. Materials Park: ASM International; 1991.

16 Pujante J, Pelcastre L, Vilaseca M, Casellas D, Prakash B. Investigation into wear and galling mechanism of aluminum alloy-tool steel tribopair at different temperatures. Wear. 2013;308(1-2):193-198.

17 Alves C, Araújo FO, Souza MRR. Comparison of plasma-assisted nitride techniques. Encyclopedia of Tribology. 2013;402-410.

18 Alves C, Ataíde ARP, Hajek V, Leite JP. Effects during plasma nitriding of shaped materials of different sizes. Surface and Coatings Technology. 2003;167(1):52-58.

19 Alves C, Araújo FO, Ribeiro KJB, Costa JAP, Souza RRM, Souza RSD. Use of cathodic cage in plasma nitriding. Surface and Coatings Technology. 2006;201(6):2450-2454.

$20 \mathrm{Li} \mathrm{CX}$, Bell T, Dong H. A study of active screen plasma nitriding. Surface Engineer. 2002;18(3):174-181.

21 Zhao C, Li CX, Dong H, Bell T. Study on the active screen plasma nitriding and its nitriding mechanism. Surface and Coatings Technology. 2006;201(6):2320-2325. 